\title{
Friction will be published monthly from 2022
}

\author{
Jianbin LUO \\ Editor-in-Chief \\ State Key Laboratory of Tribology, Tsinghua University, Beijing 100084, China \\ (C) The author(s) 2021.
}

In order to further reduce the publication time lag to meet this increasing demand from both our authors and readers, the journal Friction expands its publication frequency from bimonthly to monthly, effective Issue 1, Volume 10 (2022).

Friction started publishing quarterly in 2013, then transitioned its production bimonthly in 2019, and now will be expanded to a high demand for publishing monthly. This expansion meets the high-speed growth of this journal in the field of tribology. During the past nine years, Friction has earned a world-wide acceptance and received manuscripts from more than 65 countries. The number of submissions has been increasing significantly year by year, reaching 512 in 2020 and probably exceeding 600 in 2021 . Friction has published 531 articles, including 59 review articles, 457 original research papers, 14 short communications, and 1 comment. Among them, 7 articles have been selected as Highly Cited Papers and 1 become a Hot Paper by Essential Science Indicators (ESI). The average downloads per month from the journal website are greater than 10,000 times, the readers' distribution by country shows that $70 \%$ of readers come from countries other than China. The rejection rate has reached almost $80 \%$ annually for the last three years. In the forthcoming 2022, Friction will change from bimonthly to monthly. A larger volume for articles makes faster publication possible. We are here welcoming excellent researches from a broader range of authors.

Notable achievements have been made for the growth of Friction. It has been indexed by Scopus, SCI, and EI Compendex, etc. The Impact Factor (IF) of Friction has achieved a new status, i.e., the IF increasing to 6.167 and ranking 8 out of 135 (the first quartile, Q1) in the "Engineering, Mechanical" category, according to 2020 Journal Citation Reports by Web of Science. Furthermore, Friction was nominated for the journal award "The Fifth China Publishing Government Award" in 2021 and consecutively won "The Highest International Impact Academic Journals in China" award from 2016 to 2020. The journal reaching to today's status is fully credited to the enthusiastic support and contribution of our dedicated editorial board members, authors, reviewers, and our readers.

I would like to take this opportunity to thank all of the members of the editorial board, the editor staff, the reviewers, and all of our authors for their outstanding efforts in maintaining the high scientific standards of the journal, as well as look forward to receiving your continued contributions in the years ahead.

Open Access This article is licensed under a Creative Commons Attribution 4.0 International License, which permits use, sharing, adaptation, distribution and reproduction in any medium or format, as long as you give appropriate credit to the original author(s) and the source, provide a link to the Creative Commons licence, and indicate if changes were made.

The images or other third party material in this article are included in the article's Creative Commons licence, unless indicated otherwise in a credit line to the material. If material is not included in the article's Creative Commons licence and your intended use is not permitted by statutory regulation or exceeds the permitted use, you will need to obtain permission directly from the copyright holder.

To view a copy of this licence, visit http://creativecommons.org/licenses/by/4.0/.

*E-mail: luojb@tsinghua.edu.cn 